\title{
Effects of Information Feedback of Task Performance on Social Loafing
}

\author{
Atsuo Murata \\ Okayama University, Okayama, Japan
}

\begin{abstract}
Social dilemma situations in an organization, under which uncooperative behaviors frequently occur, can lead to violation of social rules, and at the worst case, it cannot help suffering from serious accidents or scandals. In a variety of social dilemma situations, it is necessary to promote cooperative behavior somehow and optimize interests of society or organization. Social loafing, in a sense, corresponds to defective behavior in a social dilemma situation. Therefore, it is important for organizational managers to take proper measures so that social loafing does not lead to serious accidents. In this study, an attempt was made to explore social loafing in order to get insights into the prevention of accidents caused by such a behavior. Controlling the number of members in a group and the information feedback condition of task performance as experimental factors, it was explored how these factors affected the social loafing under a dual-task situation where participants were required to conduct both main calculation task and secondary vigilance (monitoring) task. The number of members in a group significantly $(p<$ 0.05 ) affected the performance of the primary calculation task, and the perormance of the primary calculation task increased with the increase of the number of members in a group, and both number of members and information feedback method significantly $(p<0.01)$ affected the percentage correct in the secondary vigilance task. As the number of members increased, the performance of secondary vigilance (monitoring) task tended to decrease. The feedback of performance information by dint of information feedback on own performance of both primary and secondary tasks, or information feedback on performance of both primary and secondary as a group was found to be effective for restraining social loafing.
\end{abstract}

Keywords: social loafing, defective behavior, vigilance task, number of members, feedback of performance information

\section{Introduction}

In our society or organizations, it is one of the major issues to enhance cooperative behavior so that violation-based accidents or scandals do not damage our society or organizations. We frequently encounter a conflict between the individual motive to maximize personal interests and the motive to maximize collective interests. If all social members attempt to maximize their personal interests, all get worse. This corresponds to a social dilemma situation, and such a situation in an organization, under which uncooperative behaviors frequently occur, can lead to violation of social rules, and at the worst case, it cannot help suffering from serious accidents or scandals. In a variety of social dilemma situations (Komorita \& Parks, 1997), it is

Atsuo Murata, Ph.D., professor, Department of Intelligent Mechanical Systems, Graduate School of Natural Science and Technology, Okayama University. 
necessary to promote cooperative behavior somehow and optimize interests of society or organization. A lot of studies are carried out to enhance cooperative behavior in social dilemma situations (Axelrod, 1997, 2006; Taylor, 1997).

Laughlin, VanderStoep, and Hollingshead (1991) demonstrated the advantage of a group work, and showed that group performance was better than individual performance. It was also demonstrated that cooperative and independent systems as a group led to higher productivity (Rosenbaum, Moore, Cotton, Cook, Hieser, Shovar, \& Gray, 1980).

On the other hand, the disadvantages and the negative aspects of group work are pointed out. Groupthink (Turner, Pratkanis, Probasco, \& Leve, 1993; Turner \& Pratkanis, 1998; Janis, 1982) is most likely to occur when a group experiences antecedent conditions such as high cohesion, insulation from experts, and limited methodological search and appraisal procedures, and lead to symptoms such as illusion of invulnerability, belief in the inherent morality of the group, pressure on dissenters, self-censorship, and illusion of unanimity. Turner et al. (1993) empirically supported the evidence of groupthink. One of the major causes of the challenger space shuttle disaster is regarded to be due to groupthink, especially illusion of unanimity. In this case, although the manufacturer of O-ring recognized the risk of malfunction of O-ring under the severely cold temperature, the manufacturer agreed with the launch of the Challenger space shuttle because of illusion of unanimity.

Social loafing (Latané, Williams, \& Harkins, 1979; Williams, Harkins, \& Latané, 1981), in a sense, corresponds to defective behavior in a social dilemma situation. These phenomena also potentially lead to crucial accidents under cooperative working condition as a group. Therefore, it is important for organizational managers to take proper measures so that social loafing does not lead to serious accidents. Latané et al. (1979) showed the evidence of social loafing that one exerted less effort when one though that one was carrying out a job in a group than one worked alone.

Williams et al. (1981) demonstrated that we consistently exert more efforts when we believed that our job performance was always identifiable in a group than when our job performance was never identifiable. However, they did not provide participants with the actual feedback on their job performance, but made participants believe that their performance was always identifiable.

Williams and Karau (1991) discussed the social compensation hypothesis for the social loafing, and demonstrated that we tend to work harder collectively than individually, provided that we expect co-workers to perform poorly on a meaning task. Kerr and Bruun (1983) discussed free-rider effects, although this does not completely correspond with the social loafing. They showed that group members exert less effort in their job with the increase of the perceived dispensability of their efforts for the success as a group.

In this study, an attempt was made to explore the social loafing in order to get basic insights into the prevention of accidents caused by this phenomenon. Using a dual-task experimental paradigm, we demonstrated the evidence of social loafing where the collective performance generally degraded with the increase of the number of members in the group. It was also explored how the feedback of each member's performance or the performance of the group as a whole was effective for restraining social loafing.

\section{Problems and Aim}

It is possible that social loafing leads to a crucial accident. On February 19, 2008, the Japanese Aegis-equipped destroyer "Atago" that belonged to Japanese Ministry of Defense collided with the fishing boat 
"Seitokumaru". Consequently, two crews of the fishing boat were missing and thereafter identified as dead. One of the main causes of this accident is inferred as follows. Although 24 crews were working (on duty) on the Aegis-equipped destroyer when the accident occurred at about 4 a.m., nobody properly noticed the fishing boat, and thus could not take a proper countermeasure against the collision. In spite of many crews on duty, every crew must optimistically reckon that someone would notice the fishing boat, if any. This corresponds to the social loafing phenomenon.

Therefore, it is important to get insights into the prevention of accidents caused by social loafing. It is expected that the feedback of each member's performance or the performance of the group as a whole helps restrain social loafing. Therefore, the aim of this study was to clarify the effect of feedback of performance of a member or a group on the restraint of social loafing.

\section{Methods}

\section{Participants}

Twelve male undergraduate or graduate students from 22 to 24 years old took part in the experiment. All signed the document on informed consent after receiving a brief explanation of the aim and the contents of the experiment.

\section{Task}

The following experiment was carried out referring to Williams et al. (1981). The main task was to add two three-digit numbers, and was self-paced. Thus, the answering time was not limited. The participants were required to conduct the main task as fast and accurately as possible. The secondary task was a vigilance task in which the participants were required to monitor the movement of vertical bar, and report as soon as possible when the bar length was beyond the predetermined limit (see Figure 1). The state in Figure 1 changed every $1 \mathrm{~s}$, and the bar length changed randomly upward or downward. The bar length was randomly beyond the predetermined limit. It was programmed so that the bar length was beyond the limit from 18 to 22 times in one experimental session. The number of members was changed from one to two, and from two to four. The participants were told that the vigilance was regarded as successful if at least one member reported the abnormal state where the bar length was beyond the predetermined limit within the duration limit $(2 \mathrm{~s})$.

\section{Design and Procedure}

Both the number of members in a group and the condition of the information feedback were within-subject factors.

The experiment was carried out separately for the group of four participants. Thus, there were a total of three groups. Four personal computers were used for the experiment of one group. It was assumed that each participant carried out the primary and the secondary tasks alone, with a 2-member group, or with a 4-member group. Using a communication function of personal computers, the performance of each participant was recorded. As for the multiple group members (2-member and 4-member groups), the mean performance data of both primary and secondary tasks were calculated on the basis of the recorded performance data of each participant, and were presented to the display in Figure 1 whenever the data was updated.

The conditions of information feedback of each member's performance or the performance of the group as a whole were controlled as follows: (1) No information on performance of both primary and secondary tasks is exhibited; (2) Information on own performance of both primary and secondary tasks is exhibited; and (3) 
Information on performance of both primary and secondary as a group is exhibited with the information on individual performance equal to the condition (2) above. The displays corresponding to the three cases (1)-(3) are shown in Figure 1. In the condition (3), the performance ranking of the primary calculation task and the number of members who reported the abnormal state properly were presented as group information.

By clicking the "start" button in Figure 1, the experiment began. The participant must simultaneously carry out the main calculation task and the vigilance (monitoring) task. In the main task, the participant must enter the answer using a keyboard. Whenever the participant noticed that the bar length was beyond the predetermined limit, he must click the "report of abnormality" button in Figure 1 as soon as possible. If the bar length was beyond the limit and the "report of abnormality" button was not clicked within $2 \mathrm{~s}$, this was regarded as an error trial.

The duration of each experimental condition was 5 mins. The order of performance of the three condition of information feedback ((1)-(3) above) was randomized across the participants. For each condition of information feedback, the performance of the conditions of number of members (alone, two, and four members) was also randomized across the participants. A total of nine experimental sessions were conducted for each participant. Between experimental sessions, the participants were allowed to take a short break of about 1 min.

The performance measure in the primary calculation task was the number of solved problems per session (5 mins). The vigilance was regarded as successful if at least one member reported the abnormal state where the bar length was beyond the predetermined limit within the duration limit $(2 \mathrm{~s})$. When at least one other member reported the abnormal state for multiple-member conditions ( 2 members and 4 members), this was regarded as successful even if the participant did not successfully report of the abnormal state. The performance measure in the secondary vigilance task was the percentage correct of successful report of abnormal state.

\section{Results}

The performance (number of solved problems) of the primary calculation task increased with the increase of the number of members in a group (see Figure 2). A two-way (number of members by information feedback method) ANOVA carried out on the number of solved problems in the primary calculation task revealed no significant main effect of information feedback method. A number of members by information feedback method interaction was also not significant. Only a significant main effect of number of members in a group $(F(2,22)=4.964, p<0.05)$ was detected. Fisher's PLSD (Protected Least Significant Difference) revealed a significant difference between one-person and four-person conditions.

As the number of members increased, the performance (percentage correct report of abnormal state) of secondary vigilance (monitoring) task tended to decrease (see Figure 3). A similar two-way ANOVA conducted on the percentage correct in the secondary vigilance task revealed significant main effects of number of members $(F(2,22)=11.288, p<0.01)$ and information feedback method $(F(2,22)=10.008, p<$ $0.01)$. A significant interaction between the number of members and the information feedback method $(F(4,44)=2.962, p<0.05)$ was also detected. Fisher's PLSD revealed the significant differences $(p<0.01)$ between the feedback condition (1) and the feedback condition (2), between the one-person and the two-person conditions, between the one-person and the four-person conditions, and between the two-person and the four-person conditions. 


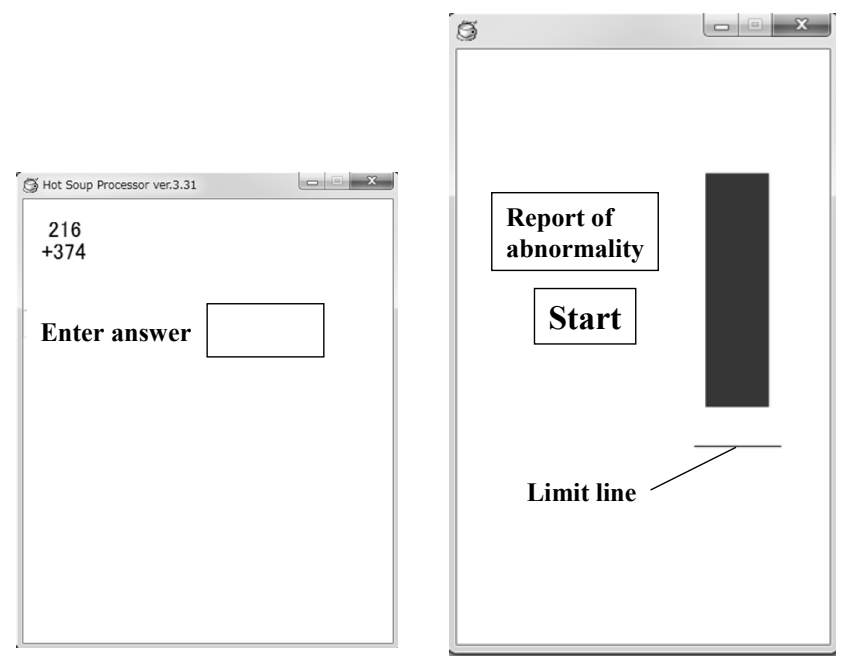

(1) no information

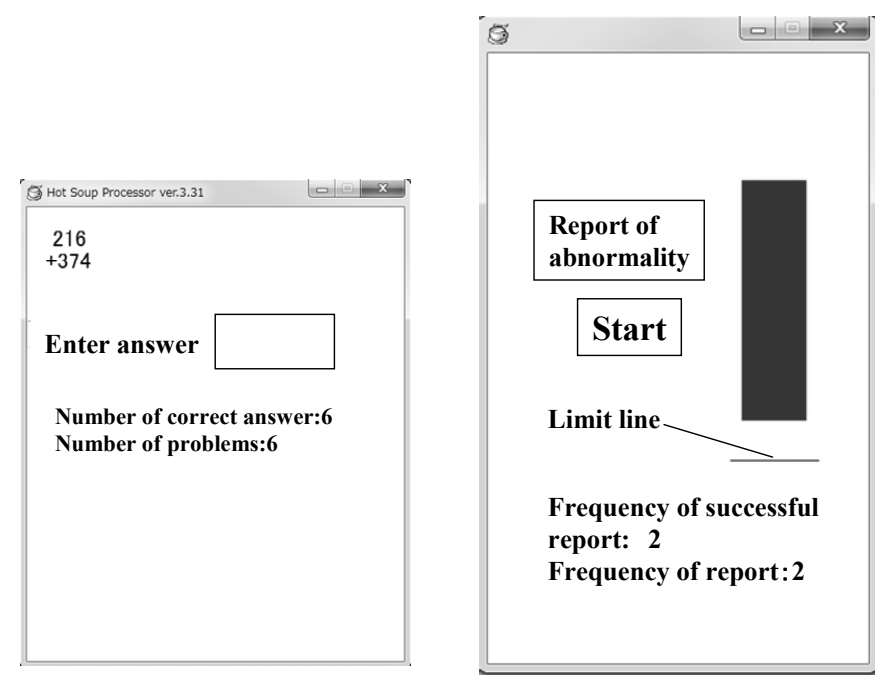

(2) own information

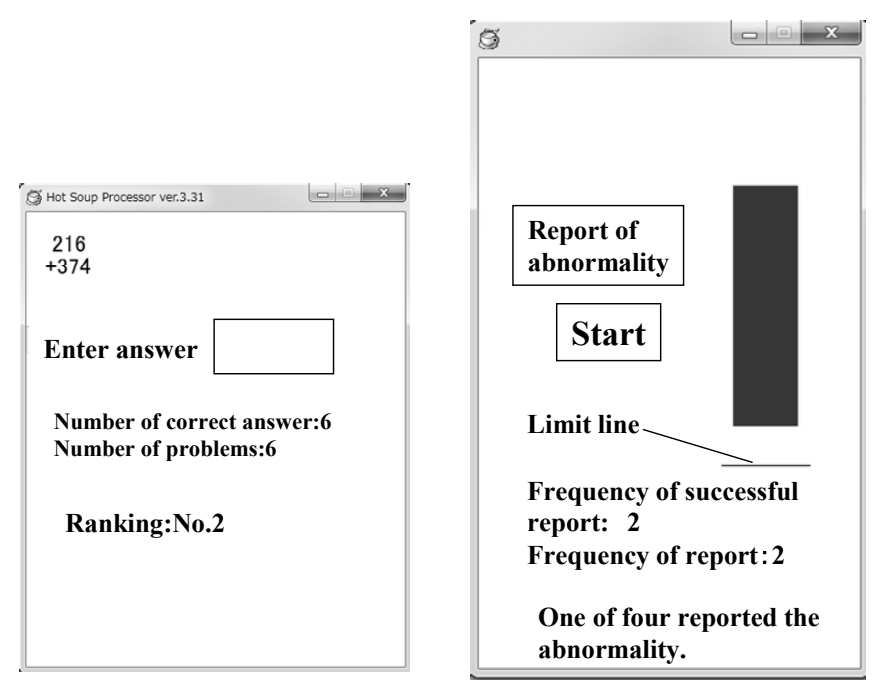

(3) information as a group

Figure 1. Displays corresponding to the three cases (1)-(3). 


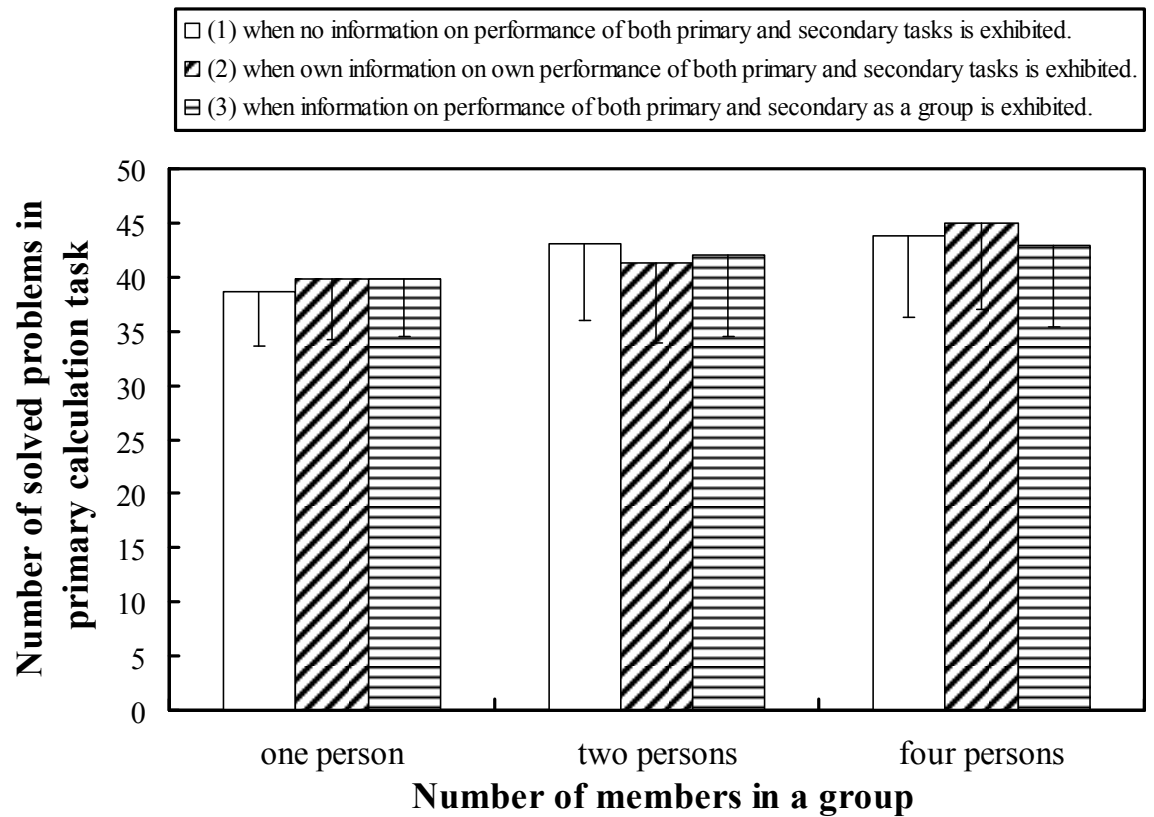

Figure 2. Mean number of solved problems in primary calculation task as a function of number of members in a group and information feedback method ((1) when no information on performance of both primary and secondary tasks is exhibited; (2) when own information on own performance of both primary and secondary tasks is exhibited; and (3) when information on performance of both primary and secondary as a group is exhibited).

$\square$ (1) when no information on performance of both primary and secondary tasks is exhibited.

$\nabla$ (2) when own information on own performance of both primary and secondary tasks is exhibited.

$\boxminus$ (3) when information on performance of both primary and secondary as a group is exhibited.

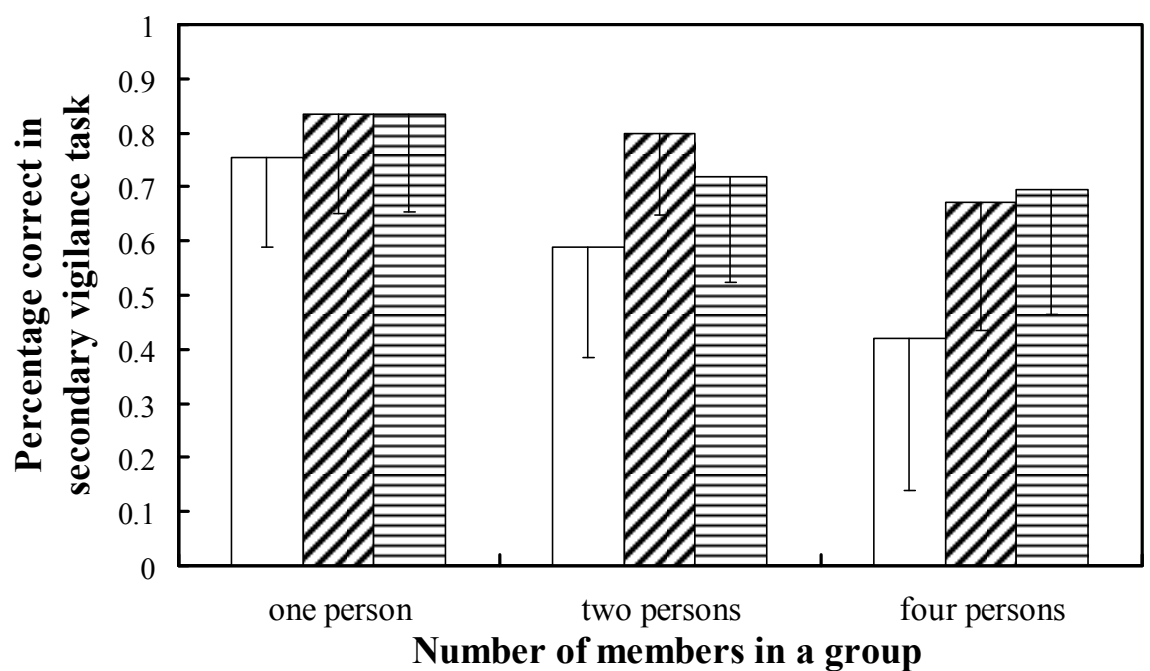

Figure 3. Mean percentage correct in vigilance task as a function of as a function of number of members in a group and information feedback method ((1) when no information on performance of both primary and secondary tasks is exhibited; (2) when own information on own performance of both primary and secondary tasks is exhibited; and (3) when information on performance of both primary and secondary as a group is exhibited).

The monitoring (vigilance) performance decreased with the increase of group members. This verified that the social loafing due to the increase of the number of members in the group occurred. This experiment also hypothesized that the feedback of each member's performance or the performance of the group as a whole 
helped restrain social loafing. As shown in Figure 3, the feedback information of performance in the monitoring task played an important role in preventing social loafing from occurring frequently.

\section{Discussion}

As shown in Figure 2, the number of solved problems increased with the increase of number of members. The increase of the number of members seemed to function so that the performance of the main calculation task is enhanced. This sacrificed the performance of the secondary vigilance task, and must eventually lead to the social loafing.

As shown in Figure 3, the performance in the secondary vigilance task decreased with the increase of members in the group. This corresponds with the result of Williams et al. (1981) and Latané et al. (1979). In short, the social loafing due to the increase of the number of members in the group was replicated and verified to occur.

As mentioned in "Problem and Aim" section, in the collision accident between the Japanese Aegis-equipped destroyer "Atago" and the fishing boat "Seitokumaru", in spite of many crews being on duty, nobody properly noticed the fishing boat, and consequently could not take a proper countermeasure against the collision. Every crew must reckon that someone would notice the fishing boat even if he did not pay attention to the vigilance (monitoring) task. This includes the characteristics of social loafing phenomenon.

The aim of this experiment was to confirm whether the information feedback of each member's performance or the performance of the group as a whole helped restrain social loafing. As shown in Figure 3, the feedback of each member's performance or performance group as a whole in the monitoring task increased the percentage correct report of abnormal state, and was effective for preventing social loafing from occurring frequently. This tendency was more remarkable when the number of members was two or four. In summary, the feedback of performance data to all members of an organization is one of the effective measures to restrain collective or organizational (social) loafing. Therefore, such a system should be delivered to all members of an organization to prevent crucial accidents which stem from the collective or organizational loafing.

\section{Conclusions}

The effect of feedback of performance of a member or a group on the restraint of social loafing was explored. The results can be summarized as follows:

(1) With the increase of number of members in a group, the percentage correct in the secondary vigilance task decreased. In such a way, the social loafing was empirically demonstrated;

(2) We found that the feedback of the monitoring (vigilance) performance was effective for restraining social loafing to some extent.

\section{References}

Komorita, S. S., \& Parks, C. D. (1997). Social dilemmas. C.O.: Boulder, Westview Press.

Axelrod, R. (1997). The complexity of cooperation. N.J.: Princeton, Princeton University Press.

Axelrod, R. (2006). The evolution of cooperation. N.Y.: New York, Basic Books.

Janis, I. L. (1982). Groupthink. M.A.: Boston, Wadsworth.

Kerr, N. L., \& Bruun, S. E. (1983). Dispensability of member effort and group motivation losses: Free-rider effects. Journal of Personality and Social Psychology, 44(1), 78-94.

Komorita, S. S., \& Parks, C. D. (1997). Social dilemmas. C.O.: Boulder, Westview Press. 
Latané, B., Williams, K. D., \& Harkins, S. (1979). Many hands make light the work: The causes and consequences of social loafing. Journal of Personality and Social Psychology, 37(6), 822-832.

Laughlin, P. R., VanderStoep, S. W., \& Hollingshead, B. (1991). Collective versus individual induction: Recognition of truth, rejection of error, and collective information processing. Journal of Personality and Social Psychology, 61(1), 50-67.

Rosenbaum, M. E., Moore, D. L., Cotton, J. L., Cook, M. S., Hieser, R. A., Shovar, M. N., \& Gray, M. J. (1980). Group productivity and process: Pure and mixed reward structures and task independence. Journal of Personality and Social Psychology, 39(4), 626-642.

Taylor, M. (1997). The possibility of cooperation. N.Y.: New York, Cambridge University Press.

Turner, M. E., Pratkanis, A. R., Probasco, P., \& Leve, C. (1993). Threat, cohesion, and group effectiveness: Testing a social identity maintenance perspective on group think. Journal of Personality and Social Psychology, 61(1), 50-67.

Turner, M. E., \& Pratkanis, A. R. (1998). Twenty-five years of groupthink theory and research: Lessons from the evaluation of a theory. Organizational Behavior and Human Decision Processes, 73(2/3), 105-115.

Williams, K. D., Harkins, S., \& Latané, B. (1981). Identifiability as a deterrent to social loafing: Two cheering experiments. Journal of Personality and Social Psychology, 40(2), 303-311.

Williams, K. D., \& Karau, S. J. (1991). Social loafing and social compensation: The effects of expectation of co-worker performance. Journal of Personality and Social Psychology, 61(4), 570-581. 